\title{
Assessment of impact of health education on non communicable diseases on knowledge of intermediate college students
}

\author{
Kumar D. ${ }^{1}$, Vikramaditya B. ${ }^{2 *}$, Shankar Joshi H. ${ }^{3}$, Kumar Jha A. ${ }^{4}$, Manjeeta. ${ }^{5}$
}

DOI: https://doi.org/10.17511/ijphr.2019.i2.05

1 Deepak Kumar, Junior Resident (Academic), Department of Community and Family Medicine, All India Institute of Medical Science, Rishikesh, Uttarakhand, India.

2* Bibhava Vikramaditya, Assistant Professor, Department of Community Medicine, SMMH Government Medical College, Saharanpur, Uttar Pradesh, India.

3 Hari Shankar Joshi, Professor and Head, Department of Community Medicine, SMMH Government Medical College, Saharanpur, Uttar Pradesh, India.

${ }^{4}$ Amit Kumar Jha, Professor, Department of Community Medicine, SMMH Government Medical College, Saharanpur, Uttar Pradesh, India.

5 Manjeeta, Junior Resident, Department of Community Medicine, SMMH Government Medical College, Saharanpur, Uttar Pradesh, India.

Introduction: There has been a rapid rise in the prevalence of non communicable diseases. Still there is ignorance with regard to their prevention in the general population. Further the preventive measures are not covered in the school curriculum. Objective: The study was done to provide information about the effectiveness of community-based health education on non communicable diseases among intermediate college students. Methods: The cross sectional study was carried out at Government Intermediate College. A health education programme of the intermediate class students was conducted. The impact was evaluated by comparing the pre and post test proformas filled by 133 students. The proforma consisted of 16 questions related to different non communicable diseases. Results: The 16 questions proforma was grouped 4 under categories. In pre test $35.5 \%$ correct answers were obtained which increased to $69.0 \%$ in the post test. ( $p=$ 0.0000). Significant improvement in knowledge was seen in all categories of questions which included Cardiovascular disease $(p=0.0000)$; hypertension $(p=0.0000)$; diabetes $(p=0.0000)$ and obesity $(p=0.0000)$. Conclusion: The findings of current study suggest that knowledge of students significantly improved after health education. Thus, health education programmes should regularly be conducted for improving the knowledge of students.

Keywords: Health Education, Non communicable diseases, Knowledge, College students

\section{Corresponding Author}

Bibhava Vikramaditya, Assistant Professor, Department of Community Medicine, SMMH Government Medical College, Saharanpur, Uttar Pradesh, India.

Email: vikramadityabibhav@gmail.com

\section{How to Cite this Article}

To Browse

Kumar D, Vikramaditya B, Joshi HS, Jha AK, Manjeeta. Assessment of impact of health education on non communicable diseases on knowledge of intermediate college students. Public Health Rev Int J Public Health Res. 2019;6(2):76-81.

Available From

https://publichealth.medresearch.in/index.php/ijphr/

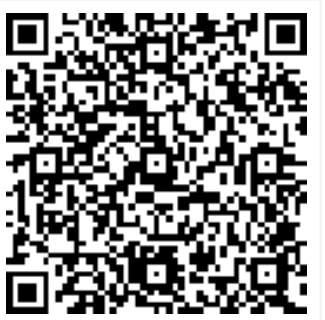
article/view/103
Manuscript Received 2019-04-08

Conflict of Interest No

Review Round 1
2019-04-18
Funding
Nil

$\begin{gathered}\text { Review Round } 2 \\ 2019-04-25\end{gathered}$
Ethical Approval
Yes

Review Round 2 Yes
Review Round 3

Accepted 2019-04-30

Plagiarism X-checker $8 \%$

() 2019 by Deepak Kumar, Bibhava Vikramaditya, Hari Shankar Joshi, Amit Kumar Jha, Manjeeta and Published by Siddharth Health Research and Social Welfare Society. This is an Open Access article licensed under a Creative Commons Attribution 4.0 International License https://creativecommons.org/licenses/by/4.0/ unported [CC BY 4.0]. 


\section{Introduction}

There has been a rapid rise in the prevalence of non communicable diseases worldwide.All countries are facingchallenges in reducing the disease burden, premature mortality and economic impact of Noncommunicable Diseases (NCDs).

Even in developing countries non communicable diseases contributes largest chunk of morbidity and mortality. With change of lifestyle from rural to urban there has been rise in non communicable diseases. Sedentary lifestyle is increasingly becoming more common.

NCDs kill 41 million people every year majority of which occur in low-and middle- income countries, confirming that these are no longer considered diseases of the affluent. Out of these, 15 million people die before reaching age of 70 years. In low and middle income countries over $85 \%$ of these premature deaths occur.

This adversely affects productivity and socioeconomic development. Cardiovascular diseases account for most NCD deaths (17.9 million people annually), followed by cancers (9.0 million), respiratory diseases (3.9 million), and diabetes (1.6 million) [1].

Global projections (2004 to 2030) indicate that NCDs, notably Cardiovascular Diseases and Cancers, are likely to rise in the coming years unless drastic measures are taken to prevent and effectively manage NCDs and their risk factors (tobacco and alcohol use, physical inactivity, unhealthy diet rich in salt, sugar and saturated/ trans-fats, air pollution) [2].

India is also experiencing a growing burden of NCDs claiming over 5.87 million lives in a year. The probability of dying between the ages of 30 and 70, from four major NCDs (cardiovascular diseases, cancer, chronic respiratory diseases and diabetes) for both sexes is as high as $26 \%$ [3].

India needs to introduce policies and interventions to reduce risk of NCDs. In the year $2011,53 \%$ of all deaths were due to NCDs and this proportion has gone up to $60 \%$ in 2014 . On the other hand, the proportion of deaths due to all communicable diseases, maternal, perinatal causes and nutritional disorders has reduced from $37 \%$ to $28 \%$ in the same period [4].

There are estimated 2.8 million cases of cancer, 39
Million with chronic respiratory diseases, 64 million with cardiovascular diseases and 69 million people with diabetes in India [5].

Economic impact of NCDs in India (2012-2030) can be judged from a study which estimates that the cumulative cost associated with CVDs, diabetes, chronic respiratory diseases and mental health was Rs. $38,302,200$ crores in 2010 [6]. Up to 80 percent of Indians incur huge out pocket expenses on medical care, resulting in debt and devastation; 39 million Indians are pushed into poverty annually, due to diagnostic and treatment costs [7].

The Indian Council of Medical Research India Diabetes (ICMR-INDIAB) study conducted by Anjana et al. (2011) showed that the weighted prevalence of diabetes was $10.4 \%$ in Tamilnadu, $8.4 \%$ in Maharashtra, $5.3 \%$ in Jharkhand, and $13.6 \%$ in Chandigarh. It also showed that age, male sex, family history of diabetes, urban residence, abdominal obesity, generalised obesity, hypertension and income status were significantly associated with diabetes [8].

Still there is ignorance with regard to the prevention of NCDs in the general population. Majority of people do not know the basic preventive measures and the major risk factors that may predispose them to these diseases. Severalresearch studies done in India have shown that adolescents have poor knowledgeabout NCDs and their risk factors [9-12].

Health education for prevention of NCDs is not covered in the school and college curriculum. Due to lack of awareness towards risk factors of NCDs adolescent students often adopt harmful lifestyles which lead to occurrence of non-communicable diseases in later adult life.

Thusthe present study was planned to provide health education on non communicable diseases and their risk factors to the intermediate college students and measure its impact on their overall understanding of prevention, early diagnosis of non communicable diseases.

\section{Aim \& Objectives}

Aim: To evaluate the impact of providing health educationprogramme.

\section{Objectives}

01. To provide health education on non communicable diseases to the intermediate 
College students.

02. To assess the awareness regarding NCDs and their risk factors among intermediate college students.

03. To evaluate the increase in knowledge of students by Pre and Post training evaluation.

\section{Material and Methods}

Study Setting: The present study was conducted at Government Intermediate College in January 2019. The college is located in ruralfield practice area of Department of Community Medicine, SMMH Government Medical College, Saharanpur.

Study Design: The present study is a cross sectional study. The impact of intervention of health education was measured by the improvement in scores of pre training assessment compared to post training evaluation.

Sampling Method: The Government Intermediate College was randomly chosen among all Intermediate Colleges in ruralfield practice area of Department of Community Medicine, SMMH Government Medical College. All students of class XI and XII (intermediate classes) present in the college at the time of the health education sessions were included in the study.

Ethical Consideration and permission: $A$ prior permission from the college administration was sought, and the purpose of the study was explained to the Principal and teachers of the college. Informed written consent was taken from all participants after explaining to them the purpose of the study. The study was duly approved by the Institutional Ethics Committee of SMMH Government Medical College, Saharanpur.

\section{Inclusion Criteria}

01 . All studentspresent on the day.

02. Those who were willing to participate in the study.

\section{Exclusion Criteria}

01 . The students who were absent on the study day.

02. Refusal to participate.

Procedure of data collection: Doctors from Department of Community Medicine, SMMH Government Medical College, Saharanpur conducted health education programme of the intermediate class students at Government Intermediate College. The students were health educated regarding
Various aspects of the non communicable diseases.

A total of 2 sessions were held of half hour each. The first session comprised of health education on cardiovascular disease and hypertension. The second session comprised of health education on diabetes and obesity. Before and after the sessions the knowledge of students was tested by administering the pre-designed, pre-tested proforma.

Development of Proforma: The proforma with questionnaire was developed by faculty members of Department of Community Medicine, SMMH Government Medical College, Saharanpur. The proforma was designed so as to contain questions on various aspects of the four diseasescardiovascular disease, hypertension, diabetes andobesity.

The questionnaire was pilot tested on 30 class XI students from other Government college which was not included in this study. Necessary changes in proforma were made after the pilot study. The corrected proforma was reviewed by the senior Community Medicine faculty members.

Scoring system: The proforma consisted of 16 questions with 4 questions on each of the non communicable diseases. The impact was evaluated by comparing the scores in pre and post test proformas. The students were explained that the proforma consisted of questions pertaining to awareness of non communicable diseases and their risk factors. Each question had only one correct response. Each correct response was given one mark. There was no negative marking.

The questionnaire was distributed before and after the sessions by the doctors with help of college teachers and collected back after 20 minutes. Care was being taken that the proformas were filled individually by students under the direct observation of the health educators and college teachers. After scoring was completed the intermediate college students were informed about their improvement in individual scores.

Statistical methods and analysis: The data collected was tabulated in MS Excel Spreadsheet and analyzed using appropriate statistical techniques like percentage, paired t-test, chi-square test and p-value using MS Excel and Epi Info and IBM SPSS version 22. Chi square test was used for evaluating statistical significance with two-tailed $p$ value less than 0.05 was considered significant. 


\section{Results}

A total of 133 students filled the proforma. All the students were in the age group of 15 years to 19 years. The study group comprised of $79(59.4 \%)$ male students and 54(40.6\%) female students.

The 16 questions proforma was grouped 4 under categories viz. Cardiovascular disease, Hypertension, Diabetes and Obesity. The mean score in pre test was $5.684 \pm 2.709$ and the mean post test score was $11.045 \pm 2.992$. (Paired $\mathrm{t}=$ $20.832, p=0.0000,95 \%$ C.I. $=4.8518-5.8700)$ (Fig. 1)

Before the health education session students were found to have the best knowledge about Hypertension (37.59\%) while least about Diabetes (33.46\%). After the health education session significant improvement in knowledge was seen in all categories of questions which included Cardiovascular disease $(p=0.0000)$; hypertension $(p=0.0000)$; diabetes $(p=0.0000)$ and obesity ( $p$ $=0.0000)$. In pre test $35.5 \%$ correct answers were obtained which increased to $69.0 \%$ in the post test. $(p=0.0000)$ (Fig. 2)

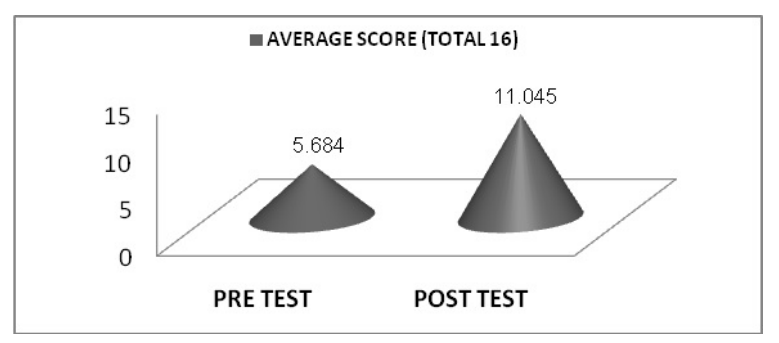

Fig-1: Mean Scores of Pre Test and Post Test

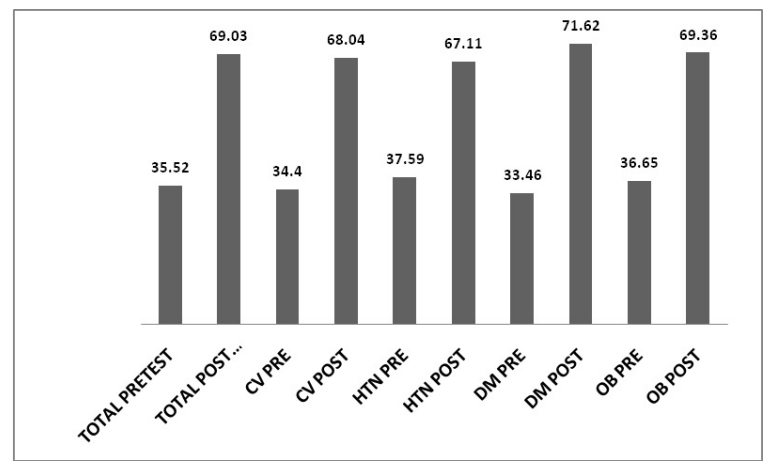

Fig.2: Comparative Percentage Scores of Pre Test and Post Test

\section{Discussion}

With improving life expectancy and lower mortality from infectious diseases, on communicable diseases
Have become the leading cause of mortality. The awareness and knowledge of general population is a key factor in prevention of non communicable diseases.

Several studies have been conducted on students for awareness of NCDs from different parts of India and abroad. While comparability of these studies are obviously be limited as awareness has multiple determinants, some are quoted for their scope. In the present study, the awareness of non communicable diseases and their risk factors was low $(35.5 \%)$ among the intermediate college students before the health education sessions.

Study conducted by Mane et al. among 226 government high school students and 298 private high school students of Davangere city, Karnataka reported government students were having poor knowledge about NCDs and their risk factors[9].

Similar findings were reported by study conducted in 375 government school children in Kerala in 2010 by Divakaran et al. [10] Another study by Batlish et al. conducted in Pune, Maharashtra, among 9th12 th class students found awareness about NCD risk factors to be very low [11].

In the present study, the knowledge of the intermediate college students regarding cardiovascular risk factors was found to be $34.4 \%$ while in study conducted by George et al. the knowledge of the school children of class 6 to 8 of Delhi regarding cardiovascular risk factors was found to be $15.3 \%$ [12]. The difference may be attributed to the higher age group of students chosen in the present study.

The present study reported the awareness about hypertension and diabetes mellitus was $37.6 \%$ and $33.5 \%$ respectively. In contrast, Goel et al. reported $65.3 \%$ and $58.3 \%$ knowledge about hypertension and diabetes mellitus among senior secondary school students of Chandigarh [13], whereas Ade et al. reported that $50 \%$ of the students had heard of cardiovascular diseases, diabetes mellitus, and cancer [14]. Lower awareness about NCDs in our study population could be due to rural area students with lower socioeconomic status with less exposure to electronic media.

However, Shivalli et al. reported $30.5 \%$ and $27.3 \%$ rates of awareness among intermediate school students from Varanasi which is comparable to our study findings [15]. Similar findings were reported in study by Chaudhari et al. which concluded that 
Baseline knowledge of students regarding risk factors of hypertension was unsatisfactory [16]. Similarly, knowledge about risk factors of hypertension was present in only a third of the Thai students and lifestyle-related risk factors which were common to all cardiovascular diseases were not well known in the study by Lorga et al [17].

In the present study, the students were given health education session regarding the various preventive measures for non communicable diseases. The mean score improved significantly in post test. Significant improvement in knowledge was seen in all categories of questions after health education session.

Study conducted by Gupta et al. among 159 government intermediate school students and 194 private intermediate school students of rural block of Jammu, Jammu and Kashmir, with comparable age group to our study, concludes that there is a need to reinforce the knowledge among adolescents in those areas about NCDs where they are lacking some knowledge [18].

Study conducted by Chakma et al. among 450 students from two coeducational colleges of Delhi University showed unhealthy lifestyle with a high burden of lifestyle related risk factors of NCDs among students and concluded that frequent campaigns and educational seminars are to be encouraged for the adoption of healthy life style and health promotion among students [19].

Similar findings were reported by Shah et al. study conducted in 627 students of three commerce colleges of Ahmedabad city which reported high prevalence of obesity in students and found significant improvement in the knowledge regarding NCDs of students after single educational session [20].

Health education of school and college students in India can be used as a major intervention for the primordial prevention of NCDs. Rapidly changing epidemiological and mortality trends in India urgently calls for strong, cohesive response. Delayed diagnosis and treatment of NCDs increases financial expenses.

Thus, prevention and early diagnosis should be strengthened. Health education of students can be effective tool for strengthening primordial prevention.

\section{Conclusion}

Primordial prevention of non communicable diseases is very important cost effective efficient tool for reducing the burden of disease. Major pillar of primordial prevention is individual and mass health education.

Health education about non communicable diseases is not imparted in the school and college curriculum in India. In this study, the findings suggest that before the session majority of students did not know the concept of prevention of non communicable diseases. Knowledge of students significantly improved after health education.

Recommendations: Health education programmes can regularly be conducted in all the schools and colleges for improving the knowledge of students on NCDs. There is urgent need to increase awareness of adolescents via education and motivation.

\section{Limitations}

The study was limited to the college of rural Saharanpur. Similar studies should be conducted in different geographical areas with a larger sample size to generalize the findings. All non communicable diseases risk factors, such as stress, waist circumference were not included in the study. The results may be influenced by social desirability.

Relevance of the study: The present study stresses the need of health education interventions on a regular basis to improve knowledge and awareness among adolescent students to discourage them from adopting harmful lifestyles which cause non-communicable diseases.

\section{Acknowledgements}

The authors thank the participant students and teachers of Government Intermediate College.

\section{Authors Contribution}

- Deepak Kumarworked in data collection and literature search and data analysis.

- Bibhava Vikramaditya was principal investigator and wrote the

- Hari Shankar Joshi guided in editing manuscript for intellectual relevance and reviewed corrected proforma.

- Amit Kumar Jha guided in study design, finalization of manuscript and reviewed 
Corrected proforma.

- Manjeeta helped in data collection and data tabulation.

\section{Reference}

01. World Health Organization. Noncommunicable diseases. 2018 [cited 2019Mar 30].

Available from: [Article] [Crossref]

02. World Health Organization. Global Status Report on Noncommunicable diseases. 2014 [cited 2019Mar30].

Available at: [Article] [Crossref]

03. World Health Organization. Noncommunicable Diseases Country Profiles. 2014 [cited 2019 Mar 30].

Available at: [Article] [Crossref]

04. Srivastava R K, Bachani D. Burden of NCDs, Policies and Programme for Prevention and Control of NCDs in India. Indian J Community Med. 2011[cited 2019 May 29];36, Suppl S1;7-

12.

[Crossref]

05. Harvard Initiative for Global Health. The economic impact of Non-communicable Diseases in China and India- Estimates, projections and comparisons. 2013 [cited 2019 Mar 30].

Available from: [Article] [Crossref]

06. World Health Organization. World Health Statistics. 2012 [cited 2019 Mar 30].

Available from: [Article] [Crossref]

07. Ministry of Health and Family Welfare. National Action Plan and monitoring framework for prevention and control of Non-communicable Diseases in India. 2012 [cited 2019 Mar 30]. Available from: [Article] [Crossref]

08. Anjana RM, Pradeepa R, Deepa $M$, et al. Prevalence of diabetes and prediabetes (impaired fasting glucose and/or impaired glucose tolerance) in urban and rural Indiaphase I results of the Indian Council of Medical Research- India Diabetes (ICMR-INDIAB) study. Diabetologia. 2011;Dec;54(12)3022-7. doi: [Article] [Crossref]
09. Mane KS, Maganalli A, Nawaz AS. A comparative study on awareness about non-communicable diseases and their risk factors among government and private high school students of Davangere city. Int J Med Sci Public Health. 2016;5(10)2026-2029. doi: [Article] [Crossref]

10. Divakaran B, Muttapillymyalil J, Sreedharan J, et al. Lifestyle riskfactors of noncommunicable diseases- awareness among school children. Indian J Cancer. 2010 Jul;47;Suppl-1;9-13. doi: [Article] [Crossref]

11. Batlish R, Jadhav SL, Banerjee A. Coronary heart disease- awareness of risk factors and lifestyle among school-going adolescents. Indian J Med Sci. 2007;Aug;61(8)474-6. [Crossref]

12. George GM, Sharma KK, Ramakrishnan S, et al. A study of cardiovascular risk factors and its knowledge among school children of Delhi. Indian Heart J. 2014; May-Jun;66(3)263-71. doi: [Article] [Crossref]

13. Goel S, Singh A. Health awareness of high school students. Indian J Community Med. 2007;32(3)192-4. Available at:

[Article] [Crossref]

14. Ade A, Chethana KV, Mane A, Hiremath SG. Non-communicable diseases- Awareness of risk factors and lifestyle among rural adolescents. Int J Biol Med Res. 2014;5(2)3769-71. doi: [Article] [Crossref]

15. Shivalli S, Gupta M, Mohaptra A, Srivastava R. Awareness of non communicable diseases and their risk factors among rural school children. Indian J Community Health [Internet]. 31Dec 2012; 24(4)332-5. Available at:

[Article] [Crossref]

16. Chaudhari AI, Rami K, Thakor N. Assessment of knowledge regarding noncommunicable diseases and their risk factors among students of higher secondary school- an interventional study. Int J Med Sci Public Health. 2016; 5(1)115-118. doi: [Article] [Crossref]

17. Lorga T, Aung MN, Naunboonruang $P$, et al. Knowledge of communicable and noncommunicable diseases among Karen ethnic high school students in rural Thasongyang, the far northwest of Thailand. Int J Gen Med. 2013 Jul; $1 ; 6 ; 519-26$.

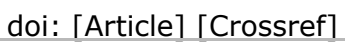


18. Gupta RK, Kumari R, Hussain S, Raina SK, Langer B, Parveen Z. A cross-sectional study to evaluate awareness about noncommunicable diseases among rural adolescents in North West India. J Dent Allied Sci. 2018;7(2)60-4. doi: [Article] [Crossref]

19. Chakma JK, Gupta S. Lifestyle practice and associated risk factors of noncommunicable diseases among the students of Delhi University. Int J Health Allied Sci. 2017 Jan-Mar; 6(1)20-5. doi: [Article] [Crossref]
20. Shah V, Jain UJ, Thakor N. Impact of educational intervention regarding hazards of obesity and its preventive measures among students of commerce colleges of Ahmedabad city, Gujarat, India. Int J Res Med Sci. 2016 Sep;4(9)3820-3. doi: [Article] [Crossref] 